\title{
Unprecedented massive reproduction aggregation of Gymnodoris ceylonica
}

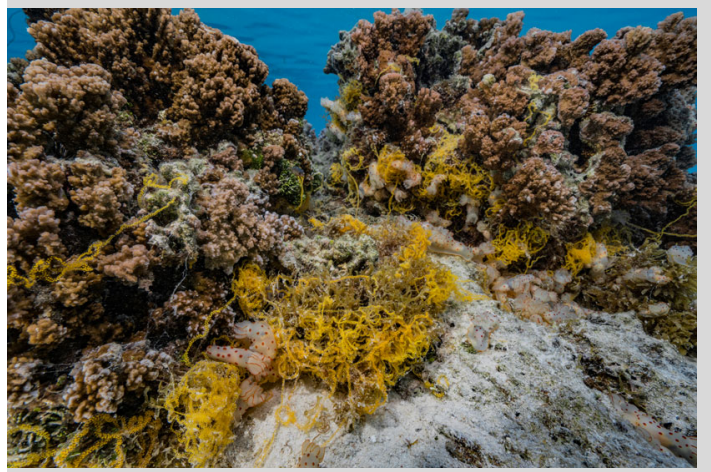

Fig. 1 Individuals of Gymnodoris ceylonica gathered in and around a coral colony (Montipora sp.), associated with massive loose egg string deposition.

Photograph credits: Alexis Rosenfeld

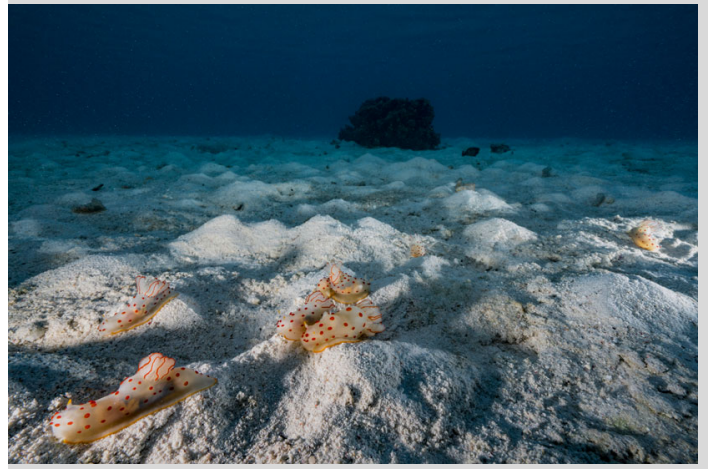

Fig. 2 Coordinated movements of nudibranchs, full or empty of eggs, migrating in the same direction over the sand area.

Photograph credits: Alexis Rosenfeld
Opisthobranchs are hermaphrodite benthic animals that occur in seas worldwide. Mostly seen alone or in small groups, mass aggregations (from 30 up to hundred individuals) of nudibranchs have been reported for feeding or reproduction purposes (Claverie and Kamenos 2008). Gymnodoris ceylonica occurs in the Indo-Pacific area and is known to migrate by dozens to reproduce (Huang 2010). Here we report an exceptional massive aggregation of $G$. ceylonica occurring in the lagoon of Temae, Moorea Island, French Polynesia (Fig. 1). More than a thousand individuals were documented to reproduce from March 2 to 4,2018 , starting one day after the full moon, over a sand area of $500 \mathrm{~m}^{2}$ (east point: $17^{\circ} 29^{\prime} 53.04^{\prime \prime} \mathrm{S} 149^{\circ} 45^{\prime} 23.88^{\prime \prime} \mathrm{O} /$ west point: $17^{\circ} 29^{\prime} 54.25^{\prime \prime} \mathrm{S} 149^{\circ} 45^{\prime} 31.31^{\prime \prime} \mathrm{O}$ ) and at $2 \mathrm{~m}$ depth. Individuals were gathering on or under rocks associated with massive egg string deposition that were mostly loosely made (Fig. 1). G. ceylonica also aggregated on a large surface "aggregation field". Coordinated movements of nudibranchs were reported over the sand area with dozens of individuals migrating in the same direction (Fig. 2). This direction changed over day time: $G$. ceylonica were migrating to the barrier reef in the morning and to the shoreline in the afternoon.

Migrating individuals were either full or empty of eggs irrespective of the direction (Fig. 2). With their nocturnal and cryptic activity, nudibranch biology still remains unclear and such events may help to better understand the biology of these species.

Acknowledgements We are grateful to David Lecchini, Isabel Ender and Laetitia Hédouin for their useful comments, and Yann Lacube for field assistance.

\section{References}

Claverie Thomas, Kamenos Nicholas A (2008) Spawning aggregations and mass movements in subtidal Onchidoris bilamellata (Mollusca: Opisthobranchia). Journal of the Marine Biological Association of the United Kingdom 88(1):157-159

Huang Hsin-Drow (2010) Field Observations of Group Reproduction in Gymnodoris ceylonica (Kelaart, 1858) (Gastropoda: Nudibranchia) at Lanyu (Orchid Is.), Taiwan. Coll. and Res. 2010(23):37-41

Electronic supplementary material The online version of this article (https://doi.org/10.1007/s00338-018-1694-x) contains supplementary material, which is available to authorized users.

C. Berthe $(\bowtie)$

USR 3278, EPHE/PSL, CNRS-UPVD, CRIOBE, 98729 Moorea, French Polynesia

e-mail: cecile.berthe@ hotmail.fr

C. Berthe

Laboratoire d'Excellence "CORAIL”, 98729 Moorea, French Polynesia

A. Rosenfeld

Association Divergence Images, Paris, France

URL: http://www.divergence-images.com

Received: 11 April 2018/Accepted: 9 May 2018/Published online: 18 May 2018

Coral Reefs (2018) 37:703

(C) Springer-Verlag GmbH Germany, part of Springer Nature 2018 https://doi.org/10.1007/s00338-018-1694-x 